\title{
La peligrosa naturaleza de Don Juan. Sexualidad masculina y orden social en la España de entreguerras ${ }^{1}$.
}

\author{
Nerea Aresti ${ }^{2}$
}

Recibido: 16 de marzo de 2017 / Aceptado: 27 de abril de 2018

Resumen: Este artículo se acerca a los discursos y a la práctica política de la derecha católica española durante los años veinte y treinta analizando cómo este sector expresó sus ansiedades frente al cambio social y la sed de orden a través de sus visiones de la sexualidad masculina. El impulso sexual de los hombres, representado a menudo en la figura del don Juan, fue identificado con la naturaleza indomada, la falta de ideales y el peligro revolucionario. A través de fuentes bibliográficas y hemerográficas, se analizan así los presupuestos y las contradicciones de estas políticas del cuerpo, que incluyeron un proyecto propio de intervención eugenésica.

Palabras clave: Masculinidades; Don Juan; civilización; historia de la sexualidad; historia de género; catolicismo; eugenesia.

\section{[en ]The dangerous nature of Don Juan. Men's sexuality and social order in Spain during the interwar period}

\begin{abstract}
This article examines how conservative discourses and politics during the 1920s and 1930s in Spain expressed anxiety about change and the desire to restore social order talking about male sexuality. Right-wing politicians and Catholic thinkers thought of men's sex drive -often represented by the image of Don Juan- as a force of untamed nature, lack of ideals, and revolutionary threat. I analyze the contradictions and notions behind these conservative body politics, which also included a particular project of Catholic eugenics. For this purpose, I use a wide range of primary sources, including newspapers, journal articles and books that were especially influential at the time.
\end{abstract}

Keywords: Masculinities; Don Juan; Civilization; History of Sexuality; Gender History; Catholicism; Eugenics.

Sumario. Introducción. 1. Naturaleza, sexualidad, y "sed de orden". 2. La política de los cuerpos y sus contradicciones. 3. Eugenesia y sexualidad masculina en los discursos de las derechas católicas. 4. Conclusiones.

Cómo citar: Aresti, N. (2018). "La peligrosa naturaleza de Don Juan. Sexualidad masculina y orden social en la España de entreguerras". Cuadernos de Historia Contemporánea, 40, 13-31.

1 El presente trabajo se inscribe dentro del proyecto "La experiencia de la sociedad moderna en España: Emociones, relaciones de género y subjetividades (siglos XIX y XX)", HAR2016-78223-C2-1-P, financiado por MINECO y FEDER, y del Grupo de Investigación Universitaria de la UPV/EHU "La experiencia de la sociedad moderna en España, 1870-1990, GIU14/22.

2 Universidad del País Vasco, UPV/EHU

e-mail: nerea.aresti@ehu.eus 


\section{Introducción}

En 1921, Ramiro de Maeztu anunció la llegada de una nueva hora del Don Juan en España. Maeztu relacionó esta resurrección con un momento de desorden moral, con una crisis de ideales que hacía evidentes la insuficiencia de los anteriores y la necesidad de unos nuevos, que él quería religiosos ${ }^{3}$. En aquellos tiempos de interregno moral e incertidumbre, Don Juan habría recobrado su vigencia como mito masculino, igual que lo había hecho en otros periodos críticos de la historia española. Maeztu aludió a la primera aparición de esta figura legendaria en una circunstancia espiritual de desgaste de la Contrarreforma, y a su retorno tras las guerras napoleónicas, cuando los hombres, huérfanos de ideales, se dieron cuenta de que ya no sentían ni la fe racionalista ni la revolucionaria ${ }^{4}$. En aquellos años 20, de nuevo, una profunda crisis de valores asolaba España. Esta crisis habría afectado a los nacionalismos, al liberalismo y al socialismo, e incluso la ciencia habría mostrado su debilidad como ideal en tiempos de guerra, "porque el Prometeo de la invención y del progreso, en los que los hombres habían puesto tantas esperanzas, lo mismo sirve para curar heridos en los hospitales que para fabricar gases asfixiantes". En un mundo sin principios firmes, sentenció Ramiro de Maeztu, el Don Juan se había alzado una vez más "como ejemplo irrefutable de haber fracasado el humanismo en su empeño de reducir el bien a lo que es bueno para el hombre"5.

Para Ramiro de Maeztu, el impulso sexual masculino representaba la naturaleza indomada. La falta de freno de este instinto libidinoso de los hombres era identificada con el caos civilizatorio y con la ausencia de ideales, ambos rasgos característicos, en su opinión, de aquel momento histórico. La salida que el Don Juan, símbolo del desorden sexual, ofrecía a la incertidumbre reinante era precisamente la "factibilidad de vivir sin otro empeño que los vaivenes de nuestros apetitos y caprichos". La figura del Tenorio representaba para Maeztu el orgullo egoísta y la concupiscencia. Más aún, la pulsión sexual masculina no era sino el empuje barbárico que conducía al desorden social, el temido peligro revolucionario. Y así lo dejó expresado: "No abre Don Juan la boca sin que le caiga la baba al bolchevique que vive dentro de cada hombre"7.

Las palabras de Ramiro de Maeztu nos hablan de varios fenómenos relacionados en aquel particular contexto histórico. Por un lado, apuntan a la búsqueda de referentes ante una duradera crisis de identidad nacional ${ }^{8}$. Son también representativas del clima de desencanto con respecto a las grandes narrativas políticas -particularmente el liberalismo y el racionalismo ilustrado-, un clima característico de la crisis de fin de siglo, que estuvo marcado en España por el 98. Nos hablan también de la experiencia de la Primera Guerra Mundial como guerra y revolu-

3 Maeztu, Ramiro de: “Temas de idealidad (Especial para Hermes)", Hermes. Revista del País Vasco, 72 (1921), pp. 715 y 716 .

4 Maeztu, Ramiro de: Don Quijote, Don Juan y la Celestina. Ensayos en simpatía, Buenos Aires, Espasa Calpe, 1943 (1 ${ }^{\text {a }}$ ed. 1926), p. 106.

Maeztu, Ramiro de: Don Quijote, Don Juan..., p. 107.

Maeztu, Ramiro de: Don Quijote, Don Juan ..., p. 105.

Maeztu, Ramiro de: Don Quijote, Don Juan..., pp. 78 y 96.

8 Franzbach, Martin: "Mitos de la Generación del 98: Don Juan”, en Jochen Mecke (coord.), Discursos del 98. Albores españoles de una modernidad europea, Madrid, Iberoamericana Vervuert, 2012, pp. 157-162, cit. en p. 157. 
ción a un tiempo ${ }^{9}$, y de los temores que acompañaron al crecimiento de una nueva derecha autoritaria ${ }^{10}$. Pero estas palabras están impregnadas además de una comprensión precisa de la sexualidad masculina y de su relación con los valores de la civilización y la religión, un aspecto que no ha recibido la atención historiográfica que requiere.

En las próximas páginas partiré de esta idea de identificación de la sexualidad con la falta de ideales y el desorden social, característica del pensamiento católico, para adentrarme en los discursos de las derechas sobre las masculinidades. Situaré en el centro del análisis la figura del Don Juan como símbolo del instinto sexual y de la ausencia de civilización, como mito masculino y como referente nacional, contribuyendo a una evaluación de las políticas del cuerpo masculino por las derechas en el contexto de entreguerras. La polémica en torno a los significados políticos del Don Juan, de muy larga tradición ${ }^{11}$, arreció durante el primer tercio del siglo XX, afianzándose además como un terreno simbólico de debate para la intelectualidad española ${ }^{12}$. La dictadura de Primo ofrecerá un escenario histórico particularmente propicio para el análisis de estas cuestiones. En aquel contexto de cambio, en el que la Iglesia y de las autoridades civiles y militares compartieron un empeño de regeneración de la moralidad, aflorarán con especial claridad las contradicciones de las políticas sexuales de las derechas y la doble moral como elemento constitutivo de las mismas ${ }^{13}$. Por último, dirigiré la mirada a los planteamientos de estos sectores sociales y políticos con respecto a la eugenesia, mostrando cómo un proyecto de conciliación de los principios científicos y religiosos situó de nuevo la contención de la sexualidad, vista siempre como un impulso peligroso para el orden social y de género, en el centro de sus preocupaciones.

9 Martorell Linares Miguel Ángel: “'No fue aquello solamente una guerra, fue una revolución'. España y la primera guerra mundial”, Historia y Politica, 26 (2011), pp. 17-45.

10 Perfecto, Miguel Ángel: "O pensamento antiliberal espanhol: Intelectuais e políticos antiliberais na Espanha do primeiro terço do século xx”, en Flavio Limoncic y Francisco Carlos Palomares Martinho (eds.): Os Intelectuais do Antiliberalismo. Projetos e Politicas para Outras Modernidades, Río de Janeiro, Civilização Brasileira, 2010, pp. 439-477.

11 Xavier Andreu ha desgranado estos significados en los liberalismos decimonónicos, en relación con los procesos de construcción de clase y nacional. En Andreu, Xavier: El descubrimiento de España. Mito romántico e identidad, Barcelona, Taurus, 2016, pp. 214-223.

12 Díaz Freire, José Javier: "El Don Juan de Unamuno como crítica de la masculinidad en el primer tercio del siglo XX”, en Nerea Aresti; Karin Peters; Julia Brühne (eds.): ¿La España invertebrada? Masculinidad y nación a comienzos del siglo XX, Granada, Comares, 2016, pp. 13-28, cit. en p. 16. En este debate, analiza el autor, la propuesta de Miguel de Unamuno resulta particularmente heterodoxa y desafiante de los términos del binarismo sexual. Ver también, Díaz Freire, José Javier: "Miguel de Unamuno, la feminización de la masculinidad moderna", Cuadernos de Historia Contemporánea, 39, 2017, pp. 39-58.

13 Así, desde el punto de vista adoptado para este artículo, la coyuntura de los años veinte, y particularmente de la segunda mitad de esta década, fue la que propició una mayor desarrollo de discursos sobre la sexualidad, también entre las filas conservadoras, y ello a pesar de la mayor movilización de las derechas católicas en los años de la Segunda República. Durante el periodo republicano también, y tal y como ha planteado José Javier Díaz Freire, estas derechas católicas estarían definidas por su posición, dentro del terreno de disputa común de la modernidad, por una visión de la evolución social de los siglos XIX y XX en términos de "triunfo progresivo de la naturaleza sobre la disciplina", en palabras de Ramiro de Maeztu. Maeztu, Ramiro: "Pasado y porvenir", El Pueblo Vasco, 8 de octubre de 1931, cit. en Díaz Freire, José Javier: La República y el porvenir. Culturas politicas en Vizcaya durante la Segunda República, Donostia, Kriselu, 1993, p. 135. 


\section{Naturaleza, sexualidad y "sed de orden"}

Ramiro de Maeztu compartió la "sed de orden" a la que se refirió por aquellos mismos años otro influyente ideólogo de la derecha, José María Pemán. Para este último, la Gran Guerra, al sorprender al mundo sin los sostenes tradicionales, sin apoyos trascendentales, habría hecho tambalear toda organización social y política, incluida la familia ${ }^{14}$. Ciertamente, aquellos años de inestabilidad y conflicto sociales fueron también testigos de importantes cambios en las relaciones de género y de una fuerte incertidumbre sobre el futuro de las mismas. Estas ansiedades fueron vividas y enfrentadas desde diferentes ámbitos ideológicos y fueron muchos los proyectos destinados a tornar la duda en certeza. Algunas propuestas tuvieron un carácter reformista ${ }^{15}$, pero no faltaron tampoco quienes echaron la vista atrás añorando un pasado ordenadamente estable. La actitud de estos últimos llevó a Luis Jiménez de Asúa a asegurar en 1930 que, ante el avance femenino, no eran pocos los hombres, también jóvenes, que se sentían temerosos y retornaban sus nostálgicas pupilas al ayer de sus abuelos, añorando "el hogar pretérito en que el varón fue señor absoluto" ${ }^{16}$. Al igual que los hombres a los que se refirió Jiménez de Asúa, tanto Pemán como Maeztu persiguieron la emoción reconfortante del orden, o como ya se nombró entonces, la sensación restauradora de la tranquilidad frente a las ansiedades del cambio ${ }^{17}$. Y, como era de esperar, los conceptos de desorden y sexualidad aparecieron íntimamente conectados, particulamente en el discurso católico. En palabras del doctor Daniel Sánchez de Rivera, nunca como en aquella coyuntura de caos y desgobierno había tenido que luchar la humanidad contra el oleaje encontrado de las pasiones, siendo entre estas las más bravías las de raigambre sexual, unas fuerzas "trastornadoras por excelencia de cuerpo y espíritu"18. La sexualidad alejaba a los seres humanos de su condición; o en expresión del pedagogo católico Ramón Ruíz Amado, "el hombre que deja predominar en sí los apetitos orgánicos, se bestializa"19.

El rechazo católico del cuerpo y de la sexualidad adquirió así especial visibilidad en el contexto de los años veinte, provocando que incluso los que tenían a gala no hablar de estas cuestiones optaran por participar de unos debates sociales que consideraban de graves consecuencias para el orden moral. El propio Papa Pío XI, cuando se propuso a través de la carta encíclica Casti Connubii sentar preceptos sobre el matrimonio cristiano, lamentó no poder guardar silencio "como conviene a los Santos", forzado por la necesidad de evitar los engaños del enemigo, por el

14 Pemán, José María: El hecho y la idea de la Unión Patriótica, Madrid, Imp. Artística Sáez Hermanos, 1929, pp. 94 y 92.

15 He analizado este estado de incertidumbre sobre el significado de la diferencia sexual y las propuestas reformadoras en el plano de la sexualidad en Aresti, Nerea: "La nueva mujer sexual y el varón domesticado. El movimiento liberal para la reforma de la sexualidad (1920-1936)", Arenal, 9 (2002), pp. 125-150; y en Médicos, donjuanes y mujeres modernas. Los ideales de feminidad y masculinidad en la España del primer tercio del siglo XX, Bilbao, Universidad del País Vasco, 2001.

16 Jiménez de Asúa, Luis: Al servicio de la nueva generación, Madrid, Morata, 1930, p. 86.

17 Mirando al futuro (Febrero de 1929). Artículos inspirados por el General Primo de Rivera. Junta de Propaganda Patriótica y Ciudadana, Madrid, Imp. Zoila Arcaribar y Ca, 1929, p. 5.

18 Sánchez de Rivera, Daniel: La ruta del matrimonio, Madrid, Imp. Helénica, 1929, p. 311.

19 Ruiz Amado, Ramón: La mujer fuerte. Ensayos sobre el feminismo. Conferencias familiares, Barcelona, Editorial Librería Religiosa, 1929, p. 120. 
bien y salvación de las almas ${ }^{20}$. Esta actitud activa, tanto en el terreno discursivo como en el de la práctica política, fue compartida por las derechas católicas españolas y por las autoridades eclesiásticas, quienes no dudaron en dotarse de todos los mecanismos de difusión disponibles, hasta de los más modernos, en su "obra de saneamiento moral"21. La identificación de la sexualidad con el caos y la falta de civilización tuvo, sin embargo, implicaciones muy distintas para las mujeres y para los hombres. Así, el gobierno del cuerpo femenino se constituyó en piedra angular del proyecto católico, desde una concepción de las mujeres como origen del pecado y naturaleza necesitada de control. Pero, aunque de otro modo y como veremos a continuación, también la sexualidad masculina fue señalada como una amenaza que debía ser conjurada. Debemos tener en cuenta además que se trata de un periodo en el que están en marcha proyectos de masculinización de la religión católica, tanto desde el punto de vista simbólico como de las prácticas sociales ${ }^{22}$.

De este modo, si bien la sexualidad en general fue percibida como peligro y desorden en el pensamiento católico, la femenina fue blanco predilecto de la acción preceptiva y de las políticas reguladoras de viejos y nuevos moralistas $\mathrm{y}$, de hecho, el cuerpo de las mujeres fue el campo de intervención fundamental en momentos de inestabilidad en las relaciones de género como fueron los años vein$t^{23}$. No es casual que la "Pastoral colectiva sobre la inmodestia en las costumbres públicas" estuviera dedicada íntegramente, tras este título genérico, a lo que era percibido como un problema moral de primer orden, el espectáculo bochornoso de la moda femenina ${ }^{24}$. El propio Gregorio Marañón, quien demostró tener una gran vocación normativa en cuestiones que afectaban a las mujeres, llamó la atención sobre el desequilibrio existente en las políticas sexuales de la Iglesia y de la derecha católica, presididas por una benevolencia con los pecados masculinos:

En realidad, aunque las hazañas del Tenorio pugnan absolutamente contra el dogma, la Iglesia, en la práctica, no ha extremado, fuerza es reconocerlo, su rigor contra los pecados donjuanescos. La prueba es que ninguna de las batallas dadas contra el donjuanismo, a pesar de que quebranta principios religiosos esenciales, ha partido de los obispos y sacerdotes, que tan fieramente arremeten, en cambio,

20 Pío XI: Carta Encíclica Casti Connubii. Sobre el matrimonio cristiano, art. 17, 31 de diciembre de 1930, reproducida en la página web del Vaticano (https://w2.vatican.va).

21 Así explicaban por ejemplo en 1925 la creación de una casa de radiofonía católica en la Conferencia de Metropolitanos Españoles de octubre de 1925. En Cárcel Ortí, Vicente (ed.): Actas de las conferencias de Metropolitanos Españoles (1921-1965), Madrid, Biblioteca de Autores Cristianos, 1994, p. 218.

22 Etienne Fouilloux planteó en los 90 esta cuestión para la Francia de entreguerras. Natalia Núñez Bargueño ha destacado esta idea para el caso español a través del estudio de los Congresos Eucarísticos. Ver Fouilloux, Étienne: "Femmes et catholicisme dans la France contemporaine: Aperçu historiographique", Clio. Femmes, Genre, Histoire, 2 (1995), pp. 319-329; y Núñez Bargueño, Natalia: "Cantemos al amor de los amores: religión, emoción y género en el Congreso Eucarístico de Madrid (1911)", ponencia presentada en XX Congreso de la Asociación Alemana de Hispanistas, sección 4a “¿La España invertebrada? Masculinidad y nación, 1921-1936”, Cantemos al amor de los amores: religión, emoción y género en el Congreso Eucarístico de Madrid (1911), 19 marzo de 2015, Heidelberg, Alemania (consultado el 9 de julio de 2016): https://www.academia.edu/10409584/ Cantemos_al_amor_de_los_amores_religi\%C3\%B3n_emoci\%C3\%B3n_y_g\%C3\%A 9 nero_en_el_Congreso_Eucar\% ${ }_{0}$ C3\%ADstico_de_Madrid_1911_.

23 Ver Díaz Freire, José Javier: "La reforma de la vida cotidiana y el cuerpo femenino durante la dictadura de Primo de Rivera", en Luis Castells (ed.): El rumor de lo cotidiano. Estudios sobre el País Vasco Contemporáneo, Bilbao, Universidad del País Vasco, 1999, pp. 225-57.

24 La "Pastoral colectiva sobre la inmodestia en las costumbres públicas", publicada en el Boletín del Arzobispado de Toledo, obtuvo una amplia difusión. Cárcel Ortí, Vicente (ed.): Actas de las conferencias de Metropolitanos, pp. 219-220. 
contra pecadillos que a los demás nos parecen veniales, cual es la indumentaria femenina. El Tenorio se acoge a la usual interpretación abusiva de la historia de la Magdalena, y supone que Dios tiene una amnistía especial para "los pecados del amor" 25 .

El diagnóstico de Marañón no era desatinado. Las mujeres no solo fueron el principal objetivo de los discursos y prácticas normativas en el mundo católico, sino que sufrieron además la inconsistencia que suponía la doble moral, un fenómeno que, por otro lado, no fue nunca patrimonio exclusivo de las derechas. Entiendo aquí la doble moral como un exceso normativo, como un ejercicio codificado de abuso de poder en las relaciones de género que permitió, además, que convivieran en un mismo modelo los significados contradictorios de la masculinidad. Como bien denunció la feminista Carmen de Burgos, solo un sistema de reglas convencionales podía admitir el prejuicio de dos morales distintas, de forma que la sociedad entera era capaz de censurar a la mujer mientras dejaba al varón "en completa libertad de faltar a todos los deberes que se han establecido respecto a la sexualidad"26. El giro romántico de la leyenda del Don Juan en la versión de Zorrilla, en la que el amor de Doña Inés conseguía la salvación del personaje ${ }^{27}$, colaboró también a fomentar este clima de permisividad hacia los excesos masculinos. La propia prensa de entonces destacó este contraste: "Tirso condena al infierno al seductor de Tisbea para que pague lo que hizo. Zorrilla le abre las puertas de la gloria con la llave del arrepentimiento" 28 .

A la vez, aquella versión decimonónica de la leyenda del Tenorio subrayó el papel de las mujeres como mediadoras entre Dios y los hombres. Se trataba de la redención del pecador por intercesión de la mujer pura ${ }^{29}$, cercana a cierta comprensión de la figura mariana, en una repartición de papeles tan desigual como adaptable a la frecuente identificación de las mujeres con la religión católica ${ }^{30}$. A comienzos del siglo XX, Julio Alarcón y Meléndez supo resumir los efectos de esta evolución: la

25 Marañón, Gregorio: "La vejez de Don Juan" (originalmente publicado como prólogo a Agustín, Francisco, Don Juan en el teatro, en la novela y en la vida, Madrid, Editorial Páez, 1928), en Marañón, Gregorio: Obras Completas, Madrid, Espasa-Calpe, 1966, I, p. 442.

26 Burgos, Carmen de: La mujer moderna y sus derechos, Valencia, Sempere, 1927, pp. 45 y 46.

27 Recordemos que en el mito barroco creado por Tirso de Molina fue condenado al castigo eterno, estableciendo claramente los límites en las relaciones del Burlador con las mujeres: "Los que fingís y engañáis/las mujeres desa suerte / lo pagaréis con la muerte" (acto I, escena XV). Ver Aresti, Nerea: Médicos, donjuanes..., p. 144. La amenaza se realiza en una frase dirigida no únicamente a Don Juan, sino a todos los burladores de mujeres.

28 Maese Pedro: "Las figuras del retablo. Zorrilla y 'Don Juan”, Heraldo de Madrid (2 de noviembre de 1918), p. 1.

29 Alberich, José: La popularidad de Don Juan Tenorio y otros estudios de la literatura española moderna, Gerona, Hijos de José Bosch, 1982, p. 16.

30 En su trabajo ya clásico, Barbara Welter situó en el siglo XIX un proceso de feminización de la religión, logrando un eco considerable en la historiografía de los años ochenta. Más recientemente se ha llevado a cabo una revisión de dicha tesis, desde mi punto de vista necesaria pero solo en parte convincente. Ver en esta línea Pasture, Patrick; Art, Jan; Buerman, Thomas (eds.): Gender and Christianity in Modern Europe. Beyond the Feminization Thesis, Leuven, Leuven University Press, 2012; Mínguez, Raúl: ‘¿Dios cambió de sexo? El debate internacional sobre la feminización de la religión y algunas reflexiones sobre la España decimonónica', Historia Contemporánea 51 (2015), pp. 397-426; Blasco, Inmaculada: 'Género y religión: de la feminización de la religión a la movilización católica femenina', Historia Social 53 (2005), pp. 117-36; y Andreu, Xavier: 'La mujer católica y la regeneración de España: género, nación y modernidad en Fernán Caballero', Mélanges de la Casa de Velázquez, 42-2 (2012), pp. 17-35. Las propuestas originales de la idea de feminización de la religión en Welter, Barbara: "The Feminization of American Religion: 1800-1860", en Hartman, Mary; Banner, Lois (eds.): Clio's Consciousness Raised, Nueva York, Octagon Books, 1976, pp. 137-57; y en Douglas, Ann: The Feminization of American Culture, Nueva York, Knopf, 1977. 
mujer debía asumir la "misión divina de auxiliadora y regeneradora en la incesante ascensión del hombre hacia Dios ( .) Porque si la mujer mira al cielo, y en sus ojos se refleja el cielo, el hombre que se fija en esos ojos, siguiendo la dirección de esa mirada, podría encaminarse al Cielo, a Dios" "31.

La derecha católica hizo gala así de una gran capacidad para conciliar rígidos principios morales con una práctica especialmente permisiva con los hombres y sus pecados de la carne. Y llamó a las mujeres, responsables de aquella misión redentora de las faltas masculinas, a ser ellas mismas guardianas de la doble moral. Esta llamada interpeló con éxito -tristemente- a algunas de sus destinatarias, a la vez que creó malestar y sentimiento de indignación en otras. De este modo, algunas mujeres se rebelaron contra la doble moral y exigieron para los hombres la misma rectitud que se esperaba de ellas. Y otras mujeres, como la poetisa andaluza Casilda de Antón del Olmet, prefirieron elogiar el alto grado de belleza moral femenina, defendiendo la actitud de la "esposa abandonada que resiste a toda tentación y, modelo de fidelidad, todo lo sacrifica al honor de su marido ofuscado" $"$.

No toda la derecha católica fue en aquellos años igualmente transigente con la doble moral y, de hecho, muchas mujeres encontraron atractiva la defensa por parte de los sectores más rigoristas de un único código ético para ambos sexos. Esta actitud más ortodoxa se apoyó en cuestiones de principios, pero constituyó también una pieza importante del proyecto político del feminismo católico. No debe sorprendernos el que un sector de mujeres viera en una rígida moral una buena aliada contra el abuso masculino, y las autoridades eclesiásticas supieron reconocer en esta postura una ocasión de acercamiento a la población femenina. El presbítero Celedonio León, por ejemplo, aseguró a las lectoras de La Mujer y el Trabajo, órgano del sindicato femenino de la Inmaculada, que el verdadero feminismo debía rechazar tanto el amor libre como la doble moral. Frente a ambos, destacó, el feminismo católico "afirma una sola moral para los dos sexos, una sola moral para el hombre y para la mujer", obligando a cumplir, recalcó, el mandato de castidad y el de fidelidad de los hombres dentro del matrimonio ${ }^{33}$.

En definitiva, es posible concluir que los discursos normativos católicos sobre la sexualidad pusieron en el centro a las mujeres, pero lo hicieron en un doble sentido: por un lado, desde una percepción del cuerpo femenino como pecado y naturaleza necesitada de control, frente a la cultura y la civilización definidas como masculinas; y por otro, desde una elevación moral de la feminidad, convirtiendo a las mujeres en salvaguarda de la fe y mediadoras en la salvación de los hombres. Y este doble presupuesto no exento de contradicciones delata que la identificación de la civilización con la masculinidad y de la naturaleza con la feminidad no fue estable, como tampoco lo fue el significado de la diferencia sexual ${ }^{34}$. Lo que sí constituyó un eje

31 Alarcón y Meléndez, Julio: Un feminismo aceptable, Madrid, Est. Tip. "Sucesores de Rivadeneyra”, 1908 , p. 326.

32 Antón del Olmet, Casilda de: Feminismo cristiano, Madrid, Juan Pueyo, 1931, p. 22.

33 León, Celedonio: "La mujer y las buenas costumbres", La Mujer y el Trabajo, 199 (1926), p. 3.

34 Planteo así que la relación entre las oposiciones binarias naturaleza/cultura, por un lado, y femenino/masculino, por otro, es inestable e históricamente construida. Esta inestabilidad no resta poder significante, en mi opinión, a cada una de estas oposiciones, ambas de gran capacidad ordenadora de la realidad, pero las hace trabajar en juegos de identificación variables. Cuestiono de este modo la supuesta relación constante en un argumento acerca del carácter universal de la opresión de género. Esta idea, que ha tenido mucha influencia en la historiografía, fue planteada en el artículo clásico de la pionera antropóloga feminista Sherry B. Ortner. La propia autora realizó una pertinente revisión de esta idea años después. Ver Ortner, Sherry B.: "Is female to male as nature is 
firme del pensamiento católico fue, como lo había venido siendo hasta entonces, una visión negativa de la sexualidad-naturaleza, en oposición al efecto civilizador de la fe religiosa.

En relación con este significado cultural de la naturaleza, la derecha católica se opuso persistentemente a una percepción positiva u optimista de ella y se enfrentó a quienes sostenían "la afirmación romántica de que el hombre es naturalmente bueno y está libre del pecado original" "35. Fueron muchas las voces que se alzaron contra "el postulado antropológico de que el hombre nace bueno y la sociedad le hace malo, que no es otra cosa que la doctrina de Rousseau", declarando abiertamente, como hizo Eloy Montero y Gutiérrez, que, por el contrario, "el hombre es naturalmente inclinado al mal, como afirma la Teología católica"36. O que en él permanece, aun tras el bautismo, la naturaleza viciada del hombre viejo ${ }^{37}$. Como muchos otros, el sacerdote Marcelino Lázaro Bayo explicó este efecto del pecado original en las almas, describiéndolo como un acontecimiento que habría acabado con el "estado feliz de la inocencia y justicia original" y con el orden más admirable, a la vez que habría roto "el freno que sujetaba los apetitos a la razón", desencadenando "las furias de la concupiscencia" 38 . Los efectos políticos de esta visión de la naturaleza y de la sexualidad fueron directos, porque, como afirmó Ramiro de Maeztu, si tanto nosotros como cuantos nos rodean somos "hombres caídos y débiles", "tenemos que organizar las sociedades de tal modo que se precavan contra las pasiones y maldades de los hombres" 39 .

En este tipo de discurso, la pulsión sexual masculina, no únicamente la femenina, simbolizó el desorden de la naturaleza frente a la razón natural y la fe religiosa. Y por tratarse de una visión androcéntrica, lo masculino fue considerado como la expresión más auténtica de la condición del género humano, y la sexualidad de los hombres como manifestación paradigmática de la naturaleza desordenada y la intemperancia. Ya años atrás, el que fuera médico de la familia real Antonio Piga y Pascual definió el "cáncer de la civilización" como "el desenfreno del apetito sexual, la grosera apetencia del hombre que busca a la mujer como el macho busca a la hembra" ${ }^{40}$. En un mundo en el que la lujuria había invadido la prensa, el teatro y la calle, aseguró, la sexualidad masculina era la expresión más grosera de la "bestialidad hablada"41. Por ello, el fenómeno del donjuanismo fue percibido en no pocas ocasiones como un desafío al orden divino. El propio Gregorio Marañón, menos ortodoxo desde el punto de vista católico en sus formulaciones sobre el Don Juan que los autores a los que vengo haciendo referencia, afirmó que esta leyenda se había nutrido del "prestigio de la rebelión contra el pecado de la carne atropellando la ley de Dios". "No es que [el Don Juan] desdeñe la disciplina católica", afirmó, "es que expresamente la conculca

to culture?", en. Rosaldo, Michelle Z.; Lamphere, Louise (eds.): Women, culture, and society, Stanford, C.A., Stanford University Press, 1974, pp. 68-87; y Ortner, Sherry B.: Making Gender: The Politics and Erotics of Culture, Boston, Beacon Press, 1996.

35 Maeztu, Ramiro de: "El valor de la Hispanidad. Libertad, igualdad, fraternidad", Acción Española III-13 (1932), pp. 9-18, cit. en p. 17.

36 Montero y Gutiérrez, Eloy: Neomalthusianismo, eugenesia y divorcio, Madrid, Imp. Juan Bravo, 1932 , p. 187.

37 Lázaro Bayo, Marcelino: Luchas de la castidad, Madrid, M. Álvarez, 1930, pp. 94 y 140.

38 Lázaro Bayo, Marcelino: Luchas..., pp. 199 y 35.

39 Maeztu, Ramiro de: "El valor de la Hispanidad...", pp. 13 y 14.

40 Piga y Pascual, Antonio: Relaciones entre la lujuria y las perturbaciones del instinto sexual con la criminalidad (Conferencia a los presos de la cárcel de Toledo), Toledo, Viuda é Hijos de J. Peláez, 1912, p. 8.

41 Piga y Pascual, Antonio: Relaciones entre la lujuria..., pp. 8 y 9. 
y escarnece"42. Así lo entendió también Ramiro de Maeztu, quien en sus escritos de los años veinte sobre el Don Juan, como vimos, expresó sus ansiedades a través de su visión de la sexualidad masculina. Maeztu planteó que solo la religión sería capaz de rescatar la masculinidad del caos dirigiéndola en un sentido de civilización. En sus palabras, "si no existe un Valor absoluto", "si no hay un Dios en los cielos, Don Juan tiene razón"43. La década de los años veinte fue propicia para la intervención autoritaria sobre los cuerpos, a través de unas políticas más definidas por sus contradicciones que por su coherencia.

\section{La política de los cuerpos y sus contradicciones}

Durante la dictadura de Primo de Rivera, tal y como ha puesto de relieve la historiografía sobre el tema, resultó relevante el uso del catolicismo "como instrumento para inculcar los principios de autoridad, orden y jerarquía a la población" 44 . Por otro lado, sin embargo, la estrecha relación entre la Iglesia católica y el poder político no estuvo exenta de conflictos, también en lo relacionado con las políticas de género, pues una cosa eran las ideas que inspiraban las políticas y otra definir la instancia desde la que se gobernarían los cuerpos y las almas ${ }^{45}$. Pese a estas fisuras, el dictador, que no hizo gala precisamente de una recta moral, reivindicó en sus discursos la importancia del sentimiento religioso para disciplinar los instintos. En su opinión, la religión resultaba

[ ] indispensable para que los hombres sepan amortiguar el ímpetu de sus pasiones, y esto lo dice un hombre investido del uniforme de soldado, que no hizo profesión de santidad ni de religiosidad, pero que tiene la convicción de que para moderar los apasionamientos y vencer flaquezas humanas es preciso un sentimiento de religión que, sobre constituir un código de moral, una directiva en los actos espirituales, actúe de freno ${ }^{46}$.

La religión era presentada así, en la propaganda política del régimen, como un muro de contención frente al vicio y al pecado para el conjunto de la ciudadanía -una ciudadanía definida por otro lado en términos de deber y jerarquía-. El propio golpe de Estado, que fue anunciado como derribo de un sistema lleno de fracasos e inepti-

42 Marañón, Gregorio: "La vejez de Don Juan...”, p. 441.

43 Maeztu, Ramiro de: Don Quijote, Don Juan..., pp. 109 y 111. Es interesante que para Maeztu, en contraste con la opinión de algunos de sus contemporáneos, la salvación y el perdón de los pecados de Don Juan no podía venir de una mujer, porque para él hombres y mujeres no eran mitades de otro ser, sino seres "enteros". Desde un planteamiento que cuestionaba la uniformidad de las visiones de género en la España de entonces, y que en su caso no estaba basado en la idea de total complementariedad, Maeztu afirmaba: "No somos unos carnales y otros espirituales, sino que todos somos espirituales y carnales", y por lo tanto: "No podemos esperar a que nos venga de afuera, de otro ser, la armonía de que carecemos. Tenemos que conquistarla por nuestro propio esfuerzo". Los hombres, ellos mismos, debían volver a la fe religiosa como único ideal y vía de civilización de sus instintos desordenados. En Maeztu, Ramiro de: Don Quijote, Don Juan ..., pp. 117-8.

44 Quiroga, Alejandro: "Educación para la ciudadanía autoritaria. La nacionalización de los jóvenes en la dictadura de Primo de Rivera", Historia de la Educación, 27 (2008), pp. 87-104, en p. 94.

45 Idea destacada en Díaz Freire, José Javier: "La reforma de la vida cotidiana...".

46 Primo de Rivera, Miguel: "En la fiesta de compensación familiar, el general Primo de Rivera pronunció un importante discurso", La Acción (14 de enero de 1924), p. 5. 
tudes, fue presentado como el fin de la vieja política de las concupiscencias ${ }^{47}$. Y los miembros del partido Unión Patriótica entendieron bien que las autoridades civiles y militares debían tener un papel protagonista en una empresa autoritaria que afectaba también a la sexualidad masculina. En una pequeña encuesta realizada desde el $\mathrm{He}$ raldo de Madrid acerca de la figura del Don Juan, un integrante de Unión Patriótica expresó esta convicción de forma taxativa: "La osadía, la deslealtad y la licencia de don Juan triunfan hasta que las ataja, para siempre, la espada de un militar" 48 .

La retórica contra el donjuanismo tuvo asimismo un claro significado en un sentido nacionalista, aspecto central de la política de Primo de Rivera. El mito de Don Juan aparecía fatalmente unido a la nación española, de forma que, como señaló Ramiro de Maeztu, interrogarse acerca de esta identificación resultaba simplemente ocioso: Don Juan era un símbolo netamente español, "y el desespañolizador que lo desespañolice, buen desespañolizador será"49. Maeztu se esforzó por subrayar el contraste entre este Don Juan español y su versión francesa, buscando en esta doble definición las diferencias entre dos naciones. El Don Juan de Molière era ateo y blasfemo, a diferencia del Tenorio español, católico, aunque "de tan desenfrenados apetitos y resoluciones tan prontas, que el impulso fogoso del placer no le deja pensar en la expiación extrema que le aguarda" "El . problema era, por lo tanto, vencer ese desenfreno haciendo de la religión una gobernadora eficaz de los instintos. Y en este sentido, el Don Juan era un embajador indeseable de la nación, tanto el afortunado personaje creado por Zorrilla como aquel otro Don Juan de la versión justiciera de Tirso de Molina. Víctor Pradera y Larumbe, católico ultraconservador, expresó así este doble rechazo hacia los donjuanes literarios:

El tipo del Burlador, creado por malos patriotas y jaleado por los extranjeros envidiosos de nuestra grandeza, ha sido uno de los elementos que han contribuido a formar esa leyenda negra que pesa sobre España. Es menester decir al mundo que no; que ningún hidalgo pecho hispano alberga ni ha albergado jamás la alevosía que el Tenorio muestra en las desdichadas obras de Zorrilla y Tirso, cuya representación debiera prohibirse ${ }^{51}$.

Desde los enfoques más ortodoxos, como el de Pradera y Larumbe, o desde aquellos basados en la doble moral, pero unidos todos por el afán de gobernar la sexualidad, todas las derechas se afanaron en desarrollar una correcta política de costumbres. Los sectores más cercanos al régimen, por su parte, y en ocasiones en competencia con la Iglesia, defendieron la importancia de la intervención del Estado en el auxilio de la moralidad pública agredida y asaltada en las calles, como manifestaba Pemán, una situación crítica que obligaba a una "intensa y activa política" por parte de las autoridades ${ }^{52}$. A pesar de que, como he venido señalando, el cuerpo

47 Así se podía leer en la publicación del Somatén, 36 (septiembre de 1923), Madrid, p. 5.

48 UN MIEMBRO DE UNIÓN PATRIÓTICA: "El espejo indiscreto. Opiniones sobre don Juan”, Heraldo de Madrid (20 de octubre de 1925), p. 1.

49 Maeztu, Ramiro de: Don Quijote, Don Juan..., pp. 81, 136 y 152. La identificación de la figura del Don Juan con la nación española ha sido a menudo un terreno de debate político, y también lo fue en el contexto aquí estudiado.

50 Maeztu, Ramiro de: Don Quijote, Don Juan..., p. 87.

51 Pradera y Larumbe, Víctor: "El espejo indiscreto. Opiniones sobre don Juan", Heraldo de Madrid (28 de octubre de 1925), p. 1.

52 Pemán, José María: El hecho y la idea..., pp. 218 y 219. 
de las mujeres fue terreno de intervención privilegiado, sobre todo para la Iglesia y significativamente en menor grado para las autoridades del régimen ${ }^{53}$, también el de los hombres fue objeto de atención, en el marco de una pugna por definir la masculinidad normativa y su relación con la sexualidad ${ }^{54}$.

En el modelo normativo redefinido por el régimen primorriverista, el encauzamiento de la pulsión sexual masculina, la evitación del escándalo y el orden social aparecieron íntimamente unidos. Todo ello sometido a las tensiones provocadas por la tendencia a la permisividad con las faltas de los hombres, es decir, por la doble moral. La actuación gubernamental estuvo centrada, en este terreno, en la prohibición de lo que se consideraba impúdico y grosero en las palabras dichas y escritas, y castigo de los actos escandalosos y de la ostentosa invasión del ámbito público por cuerpos peligrosos. Se trataba, según se planteó desde el rotativo progubernamental La Acción ${ }^{55}$, de una obra en dos fases, primero de limpieza y después de restauración moral, de forma que se hacía necesario comenzar por aminorar "la inmoralidad de las costumbres en su aspecto más visible como condición para [que] la obra posterior, es decir, la de reconstrucción de esas costumbres, tenga dentro de unos años la eficacia que todos apetecemos" $" 56$.

Me interesa destacar aquí que estas políticas pretendieron contribuir a la restitución de una masculinidad -nacional- que situaba en el centro del proyecto el control de los impulsos sexuales y, claro está, la heterosexualidad ${ }^{57}$. Así, la visibilidad del denominado "invertido" fue perseguida incluso a través de iniciativas individuales, como la del gobernador civil de Málaga, el general Cano, quien ordenó en 1924 "que se persiga a los invertidos que hagan pública ostentación de su cualidad y que se les afeite la cabeza y las cejas". "Hoy se ha hecho así con dos", anunciaba con júbilo la prensa más entusiasta por este tipo de políticas ${ }^{58}$. Por otro lado, como parte de este proyecto, es sabido que la blasfemia y la literatura e imagen pornográficas fueron prohibidas y perseguidas por el régimen de Primo de Rivera. En esta labor se pretendió contar con la colaboración ciudadana, llamando a la sociedad a señalar, por ejemplo, "los lugares públicos donde se exhiben y venden publicaciones obscenas" 59 . Esta implicación en la tarea de salvaguarda de la buena ciudadanía -moral y católica- se traducía en un control autoritario por parte de instituciones como el cuerpo armado del Somatén, desde una visión en la que el orden sexual y el social eran percibidos, de forma insistente, como las dos caras de una misma moneda:

53 Díaz Freire, José Javier: "La reforma de la vida cotidiana...", p. 234.

54 Ver Aresti, Nerea, Masculinidades en tela de juicio. Hombres y género en el primer tercio del siglo XX, Madrid, Cátedra, 2010.

55 Richard Cleminson, Francisco Vázquez y Pura Fernández han realizado un interesante y novedoso acercamiento al papel de los escándalos sexuales en la España de finales del siglo XIX, en un artículo en el que destacan el papel fundamental que jugó la prensa en este fenómeno. En Cleminson, Richard; Fernández, Pura; Vázquez García, Francisco: "The Social Significance of Homosexual Scandals in Spain in the Late Nineteenth Century", Journal of the History of Sexuality, 23-3 (2014), pp. 358-82, en p. 361.

56 Duque de G. [Delgado Barreto, Manuel]: "Política de costumbres. La campaña de saneamiento", La Acción (16 de mayo de 1924), p. 1.

57 Ver Vázquez García, Francisco y Cleminson, Richard: Los invisibles. Una historia de la homosexualidad masculina en España, 1850-1939, Granada, Comares, 2011.

58 [Sin firma]: “El gobernador de Málaga quiere cortar... por lo sano”, La Acción, 14 de mayo de 1924, p. 1.

59 Este tipo de llamadas fueron realizadas a menudo desde las autoridades, en este caso por Severiano Martínez Anido, ministro de la Gobernación, ante el Consejo Superior del Protección de la Infancia. En [Sin firma]: "Consejo Superior de Protección a la Infancia", $A B C$ (1 de abril de 1925), p. 14. 
Sabes de un conocido que o él o alguno de su familia blasfema, preséntate lisa y llanamente a su casa, y di al padre o madre: me consta que sois unos malos ciudadanos, por qué enseñáis a blasfemar a vuestros hijos. ¿Por qué? Os dirán. Porque me consta que ante vuestros hijos habláis mal de Dios, nuestro padre; luego, enseñáis al pueblo el desorden ${ }^{60}$.

Asimismo, las derechas plantearon, frente a lo que fue prácticamente un consenso abolicionista entre los sectores progresistas y feministas de la época, una regulación de la prostitución ${ }^{61}$. Tal legislación debía evitar el escándalo y atajar los males achacados a la prostitución clandestina, que habría adquirido, decían, proporciones de alarma nacional. En palabras de Manuel Delgado Barreto, la falta de vigilancia por la autoridad acabaría por destruir la raza: "Nuestra nación se está convirtiendo en un inmenso prostíbulo", aseguró ${ }^{62}$. Algunos de estos defensores de la reglamentación, que decían no asustarse "de nada propio de hombres" -tal era el caso de Delgado Barreto-, se esforzaron por repartir responsabilidades. Así, distinguieron entre las uniones que pertenecerían a la "esfera de acción de los dogmatizadores de la moral", para las que pedían a los sacerdotes que emplearan todos los medios de coacción y castigo a su alcance, y aquellas otras prácticas que caían de lleno "dentro de las prescripciones policíacas e higiénicas establecidas, como salvaguarda de la moral y de la salud pública". ${ }^{63}$

Autoridades religiosas, civiles y militares aprovecharon así un clima político favorable por autoritario para intervenir de forma incisiva en la sexualidad, también masculina, insistiendo entre otros aspectos en la detracción del cuerpo degenerado o abyecto, la evitación del escándalo, el rechazo de la pornografía y de la blasfemia, la reglamentación de la prostitución y la capacidad de este modelo para definir la masculinidad nacional. Para ello, la coerción externa y el freno impuesto por la moral religiosa desempeñaron un papel central. Y como sucedió en el terreno discursivo, las prácticas políticas debieron enfrentarse a las contradicciones impuestas por una doble moral instalada socialmente. Exponentes claros de estas tensiones fueron el boicot en la prensa y posterior suspensión gubernamental del Primer Curso Eugénico Español de $1928^{64}$, hechos que fueron denunciados por los sectores, digamos, progresistas, como muestra de la hipocresía moral del régimen. En este suceso, que

60 Furest Roca, Modesto: Somatenista antiblasfémico (de ambos sexos). Un momento para agradar a Dios. S.1. S.n., 1924, p. 6.

61 En su importante estudio sobre el tema, Jean-Louis Guereña ha analizado la evolución de este debate social y político de largo recorrido y su plasmación en medidas legislativas en diferentes contextos. Ver Guereña, JeanLouis: La prostitución en la España contemporánea, Madrid, Marcial Pons, 2003. Inmediatamente después del golpe de Estado de Manuel Primo de Rivera, la Sociedad de Abolicionismo y la Sociedad de Lucha Antivenérea, animada por la nueva "situación regeneradora de la política", hizo llegar al Directorio Militar una petición de supresión del reglamento de la prostitución y la "persecución de las causas que originan en las poblaciones las enfermedades secretas". En [Sin firma]: "Peticiones de la Sociedad de Abolicionismo al directorio", $A B C$ (25 de septiembre de 1923), p. 9.

62 Duque de G. [Delgado Barreto, Manuel]: "Los repugnantes crímenes del vicio. Antesalas de la degeneración y de la muerte", La Acción (16 de enero de 1924), p. 1.

63 Duque de G. [Delgado Barreto, Manuel]: "Política de costumbres. La campaña de saneamiento", La Acción (20 de mayo de 1924), p. 1.

64 Noguera, Enrique: “Como se yuguló la generosa idea del Primer Curso Eugénico Español”, en Noguera, Enrique; Huerta, Luis (eds.), Genética, Eugenesia y Pedagogía Sexual. Libro de las primeras jornadas eugénicas españolas, Madrid, Morata, Vol II, 1934, pp. 399-412. 
ha recibido una notable atención historiográfica ${ }^{65}$, una real orden interrumpió la celebración de unas conferencias porque no se podía consentir que se convirtieran en "propaganda contra la natalidad, en regodeo pornográfico, ni en ofensa ni ataque contra la moral cristiana y los fundamentos éticos de la sociedad". ${ }^{66}$ La medida contrastaba con la moral floja del dictador, sus relaciones poco decorosas y su asidua asistencia a espectáculos nocturnos. De la prohibición gubernamental de las jornadas no podemos deducir, sin embargo, una inevitable contradicción entre el punto de vista religioso y los planteamientos eugenésicos. A este aspecto precisamente, el de la eugenesia y su relación con la sexualidad dedicaré el tercer apartado de este artículo.

\section{Eugenesia y sexualidad masculina en los discursos de las derechas católicas}

La visión de la sexualidad como desorden no fue exclusiva de las derechas católicas. Lejos de ello, estuvo presente, aunque con connotaciones distintas, en una parte importante de las culturas políticas de la España de entonces. El principal debate en este punto consistió en determinar qué fuerza civilizadora "la razón científica, la religión o ambas a la vez- debía encauzar esta energía sexual, y cómo tenía que hacerlo. El debate consistía también en definir el significado de la propia moral, que para unos era un valor absoluto y para otros más bien una convención social. Estos últimos describieron la moral como un código convenido y tornadizo, como un "luminoso anuncio de cambiantes letreros", afirmando que en aquellos años ya no había nada menos efectivo que "el tono de sermón para convencer espíritus" "67. Frente a ellos, especialmente los más conservadores reivindicaron una única verdad moral y la idea de que solo la religión podía dar solución al desorden y al desgobierno espiritual de las sociedades modernas. Como aseguraba José María Pemán en 1929, "la falta de sentido religioso en el mundo moderno es la que engendra el problema más angustioso del momento actual: el problema del orden" ${ }^{68}$. En estos discursos, el orden y la estricta contención del instinto sexual podían emanar únicamente de la fe religiosa. El sacerdote y catedrático de Derecho Canónico Eloy Montero y Gutiérrez lo expresó con claridad: "la Religión es el único freno verdaderamente eficaz contra el libertinaje" "69. Siendo este un eje fundamental del pensamiento de las derechas católicas, la religión no ejerció necesariamente en solitario su labor de freno. La construcción de un proyecto eugenésico por estos sectores conservadores puso de relieve que una apropiada confluencia de los discursos religiosos y científicos podía resultar eficaz en la tarea de ordenar el instinto sexual.

Un determinado concepto de la ciencia y de la religión permitieron amparar así el desarrollo de una eugenesia católica que contribuiría al señalado fin ordenador y

\footnotetext{
65 Ver, entre otros, Pérez Sanz, Pilar; Bru Ripoll, Carmen: “La Sexología en la España de los años 30. Tomo I: 'Las Jornadas eugenésicas de 1928 y 1933”", Revista Española de Sexología, 30 (1987), pp. 1-89; y el más reciente Barrachina, Marie-Aline: "Maternidad, feminidad, sexualidad. Algunos aspectos de las Primeras jornadas eugénicas españolas (Madrid, 1928-Madrid, 1933)", Hispania, LXIV/3, 218 (2004), pp. 1003-1026.

66 OFICINA DE INFORMACIÓN: "Se prohíben las conferencias del Curso Eugénico", Heraldo de Madrid (17 de marzo de 1928), p. 1.

67 A. de M.: "La sexualidad en la calle", Sexualidad, 80 (1926), p. 15.

68 Pemán, José María: El hecho y la idea ..., p. 298.

69 Montero y Gutiérrez, Eloy: Neomalthusianismo, eugenesia..., p. 70.
} 
de control social ${ }^{70}$. Sin duda, los presupuestos católicos marcaron claras limitaciones a la política eugenésica. Reconocer el lugar que ocupaba la verdad científica con respecto a la verdad revelada resultó siempre importante para unos sectores que debían evitar la arrogancia y el error de considerar la verdad como un producto del "hombre" ". Durante años, desde la voluntad de aunar fe y razón en un ambiente de avance del prestigio de la ciencia, se había venido llamando la atención sobre el hecho de que no existía ramo alguno del saber humano que no tuviera sus secretos impenetrables ${ }^{72}$, y que el hombre debía aprender qué gran ciencia era la de ignorar. Por eso, ya en un contexto de difusión de las ideas eugenésicas, se afirmó que, cuando para mejorar la especie, el hombre quería actuar como auxiliar de la naturaleza, "se halla con que no sabe realmente lo que debe hacer. Pero no quiere confesar su ignorancia"73. Más aún, la intervención directa sobre la reproducción humana chocaba con el hecho de que esta última estaba guiada por Dios, y los mortales no podían ni debían intentar interceder en sus sagrados designios ${ }^{74}$.

Sin embargo, los límites impuestos por la fe religiosa al saber científico y a las políticas inspiradas en él no implicaron, como bien han señalado Marisa Miranda y Gustavo Vallejo, una renuncia de la derecha católica a ciertos recursos ofrecidos por la eugenesia para el control de los cuerpos y de la sexualidad. Con frecuencia, ciertamente, los ideólogos conservadores destacaron las dimensiones espirituales y morales del problema sexual frente a orientaciones puramente biológicas y antropológicas. Asimismo mostraron, tal y como hizo por ejemplo Eloy Montero, su disconformidad "con las doctrinas eugénicas negativas", aunque admitían, eso sí, "una moderada eugenesia positiva, siempre que se respeten los supremos principios de la moral y del derecho natural"75. Más que la selección de biotipos, se planteaba el perfeccionamiento de los fenotipos a través, en palabras de Antonio Vallejo Nágera, de un "acción constante sobre cada individuo para mejorarlo física y moralmente"

70 Participo así de una visión de la denominada eugenesia latina según la cual, aunque reacia a ciertas medidas de eugenesia negativa como la esterilización, no dejó de tener un profundo carácter coercitivo y de control social. Ver, entre otros, Miranda, Marisa; Vallejo, Gustavo (comps.): Darwinismo social y eugenesia en el mundo latino, Buenos Aires, Siglo XXI, 2005; Vallejo, Gustavo; Miranda, Marisa, “'Civilizar la líbido': Estrategias ambientales de la eugenesia en la Argentina”, Iberoamericana, XI-41 (2011), pp. 57-75, cit. en p. 58; de los mismos autores: "Iglesia católica y eugenesia latina: Un constructo teórico para el control social (Argentina, 19241958)", Asclepio, 66-2 (2014), disponible en http://dx.doi.org/10.3989/asclepio.2014.19, p. 2; Juárez González, Francisca: "La eugenesia en España, entre la ciencia y la doctrina sociopolítica", Asclepio, 51-2 (1999), pp. 117-131. Este planteamiento problematiza la línea interpretativa sugerida hace años por Nancy Stepan, en su estudio referido a Brasil, Argentina y México, que identificaba una eugenesia negativa autoritaria de países como Estados Unidos, Alemania o norte de Europa frente a una eugenesia ambientalista típicamente latina, amortiguada por los límites impuestos por la religión católica. Ver Stepan, Nancy L.: "The Hour of Eugenics": Race, Gender, and Nation in Latin America, Ithaca, Cornell University Press, 1991; y Mazumdar, Pauline M. H.: Eugenics, Human Genetics and Human Failings: The Eugenics Society, Its Sources and its Critics in Britain, Londres, Routledge, 1992, pp. 211-212.

71 Maeztu, Ramiro de: Don Quijote, Don Juan..., p. 136.

72 S. f. [Blanc y Benet, José?]: "Del examen de las relaciones que median entre la fe y la razón humana se desprende cuáles sean los verdaderos límites de la ciencia", El criterio católico en las ciencias médicas (19 de julio de 1899), pp. 265-267, cit. en p. 267.

73 Villaverde, José Ma: "En torno a un congreso de eugenesia”, El siglo médico (12 de mayo de 1928), pp. 515-516, cit. en p. 516.

74 Vallejo, Gustavo; Miranda, Marisa: “'Civilizar la líbido’...”, p. 58.

75 Montero y Gutiérrez, Eloy: Neomalthusianismo, eugenesia..., p. 139.

76 Vallejo Nágera, Antonio: Eugenesia de la hispanidad y regeneración de la raza, Burgos, Editorial Española, 1937, p. 77. Antonio Vallejo Nágera jugaría un papel central en la legitimación científica del régimen franquista desde el campo de la psiquiatría, tras ocupar, durante la guerra, el cargo de director de los Servicios Psiquiátricos Militares del ejército franquista. Ver Huertas, Rafael: Los médicos de la mente. De la neurología 
Y dicha acción constante encajaba perfectamente en un proyecto de moralización y recatolización -que era también para muchos ideólogos de la derecha un proyecto de higiene racial-: "Es preciso que el individuo se halle continuamente sumergido en una atmósfera sobresaturada de moralidad", un ambiente que garantizaría la continencia sexual del hombre civilizado ${ }^{77}$.

El encaje de la eugenesia en estas políticas moralizantes conservadoras se enfrentó a diversos obstáculos. El neomaltusianismo constituyó lógicamente un escollo fundamental y, no casualmente, la encíclica Casti connubii de Pio XI de 1930, a la que antes he hecho referencia, centró sus críticas en este aspecto, cerrando filas en torno a la prohibición de cualquier forma de intervención sobre la procreación ${ }^{78}$. Por otro lado también, la prevención frente a la interferencia del Estado en materias morales y religiosas jugó un papel importante. José María Pemán arremetió contra la funesta eugenesia estatista, de forma que iniciativas como el certificado médico prematrimonial, algo que por otro lado no fue rechazado por eugenistas como Antonio Vallejo Nágera, equivaldría a querer legislar sobre un sacramento ${ }^{79}$. Asimismo, argumentos apoyados en Tomás de Aquino combatieron medidas eugenésicas que eran entendidas como de amputación de órganos en los seres humanos, si bien este tipo de argumentos relacionados con la integridad corporal y la dignidad humana quedaron a menudo supeditados al protagonismo de las políticas pronatalistas y de oposición al neomaltusianismo, como quedó plasmado en estas palabras de Vallejo Nágera:

Pero los peligros dimanados de la ley de esterilización no residen en el número de esterilizaciones oficiales, sino en que autoriza y fomenta las esterilizaciones voluntarias, bajo la responsabilidad personal de los médicos, esterilizaciones cuyo número es incalculable ( ) Al legalizar la esterilización voluntaria, incrementa el neomaltusianismo, con perjuicio de la natalidad ${ }^{80}$.

A pesar de la importancia de estas líneas rojas en la definición de la eugenesia católica, existía otro aspecto relacionado con la gestión de la sexualidad que resultó también decisivo y que deseo destacar aquí. Ya en aquellos años, uno de los adalides de la eugenesia que la Iglesia condenaba, el doctor Gonzalo Rodríguez Lafora, apuntó a las contradicciones de un discurso que, afirmando basarse en valores morales inquebrantables, salvaguardaba por encima de todo el control de la sexualidad y el gobierno de los cuerpos:

al psicoanálisis, Madrid, Nívola, 2002; del mismo autor: "La psico-biología del marxismo como categoría antropológica en el ideario fascista español”, Llull, 19 (1996), pp. 111-130; y "Una nueva Inquisición para un nuevo Estado: psiquiatría y orden social en la obra de Antonio Vallejo Nágera”, en Ciencia y fascismo, Huertas, Rafael; Ortiz, Carmen (eds.): Madrid, Doce Calles, 1997, pp. 97-110. Vallejo Nágera construyó también una visión de la diferencia sexual característica de su posición con respecto a la religión y al orden social. Ver en este sentido Aresti, Nerea: "The Battle to Define Spanish Manhood", en Aurora Morcillo (ed.): Memory and Cultural History of the Spanish Civil War. Realms of Oblivion, Boston, Brill Publishers, 2013, pp. 147-177. La obra de Vallejo Nágera supone así una referencia central para el tema de este trabajo.

77 Vallejo Nágera, Antonio: Eugenesia de la hispanidad..., pp. 86 y 92.

78 La repercusión internacional de la encíclica en relación con la eugenesia ha sido objeto de atención historiográfica desde hace años. Ver, por ejemplo, para Francia y Alemania, el trabajo de Lepicard, Etienne: "Eugenics and Roman Catholicism. An Encyclical Letter in Context: Casti connubii, December 31, 1930", Science in Context, 11, 3-4 (1998), pp. 527-544.

79 Pemán, José María: El hecho y la idea ..., pp. 215-216.

80 Vallejo Nágera, Antonio: "Ilicitud científica de la esterilización eugénica”, Acción Española, I-2 (1932), pp. 142-154, en p. 150. 
La dificultad moral está en que la esterilización, por su poco mutilante efecto, suprime sólo la procreación, pero no suspende la actividad sexual, y cabe que resulte un medio anticonceptivista que la Iglesia no puede admitir. Para ella resulta, pues, más justificada una mutilación mayor, como la castración, que suprime ambas resultantes de la vida sexual sin disociarlas.

De hecho, la Iglesia católica ha permitido tácitamente la práctica de la castración durante varios siglos en los muchachos que habían de formar las voces sopranos del coro de la Capilla Sixtina. Fue Benedicto XIV el primero que se opuso a esta práctica, aunque aconsejó a los obispos que no eliminaran a los eunucos del coro ${ }^{81}$.

La relación entre la esterilización y la sexualidad fue de hecho un elemento central en el rechazo por la Iglesia de las medidas de eugenesia negativa. Hay que tener en cuenta que en los medios médicos de entonces se aceptaba comúnmente la idea de que, aunque el efecto de este tipo de operaciones podía ser imperceptible en sus efectos sobre la pulsión sexual, la esterilización -aplicada a los denominados "degenerados", débiles o deficientes mentales- podía disminuir el deseo sexual en las mujeres pero solía aumentarlo en los hombres. Ello hacía, afirmaba en otros Rodríguez Lafora, que la esterilización no fuera un método adecuado para domesticar la sexualidad masculina ${ }^{82}$. Esta idea fue generalmente compartida por los conservadores católicos, quienes insistieron en que la esterilización favorecía "la inmoralidad y las enfermedades venéreas, ya que los así esterilizados se entregan sin freno ni medida a sus impulsos libidinosos" $"$. Desde el punto de vista católico, por lo tanto, aquella discutida medida, que ganaba adeptos y se materializaba en nuevas leyes a nivel internacional, presentaba inconvenientes de índole muy diversa, entre los que el control de la sexualidad masculina tuvo un lugar relevante.

Por lo tanto, las prevenciones contra la esterilización y contra las medidas de eugenesia negativa estuvieron también relacionadas con el tema que nos ocupa, en concreto con la identificación que las derechas hicieron de estas medidas con el desorden sexual y con la desvinculación de la sexualidad del hecho procreativo. Las derechas se esforzaron por redefinir la eugenesia en términos morales, alejándola de los contenidos que adoptaba en los discursos de sus adversarios políticos, en los que, decían, la eugenesia se parecía más a la pornografía que a una verdadera ciencia. Antonio Vallejo Nágera arremetió contra lo que denominó fariseísmo eugenésico, aquel que, diciendo evitar la descendencia tarada, favorecía la prostitución y el libertinaje, "sin que esto último preocupe mínimamente a los eugenistas" $" 84$. "A nadie se le ocultan los graves inconvenientes del desenfreno sexual a que pueden entregarse hombres y mujeres esterilizados" advirtió, a la vez que alarmaba sobre el peligro que representarían unos sujetos estériles que se entregarían a todos los excesos mientras son solicitados "por compañeras que saben no corren riesgo alguno con ellos" ${ }^{15}$. En su opinión, lejos de propiciar el cumpli-

81 Rodríguez Lafora, Gonzalo: "Eugenesia práctica. La esterilización eugenésica de los degenerados. II", El Sol (7 de junio de 1930), p. 1.

82 Rodríguez Lafora, Gonzalo: "Eugenesia práctica. La esterilización eugenésica de los degenerados. III", El Sol (12 de junio de 1930), p. 1.

83 Montero y Gutiérrez, Eloy: Neomalthusianismo, eugenesia..., p. 127.

84 Vallejo Nágera, Antonio: "La ciencia y la política [Conferencia "Higiene de la raza" de Antonio Vallejo Nágera]", La Época (15 de noviembre de 1933), p. 3.

85 Vallejo Nágera, Antonio: "Ilicitud científica...", pp. 151-152. 
miento de una función profiláctica y moralmente edificante, la esterilización abría la puerta a que el individuo se entregara "a toda especie de excesos venéreos" La eugenesia negativa, se insistía, constituía una incitación a la depravación y a la perversión sexuales.

Las alternativas a la esterilización debían evitar ese tipo de peligros. Eloy Montero y Gutierrez, por ejemplo, realizó propuestas que, igualmente eugénesicas y represivas, no resultaran problemáticas desde el punto de vista de la fe y de la gestión de la sexualidad: "La solución defendida a este respecto por los católicos ha sido el aislar los sexos en colonias, donde puedan trabajar los anormales en el campo o en labores manuales" $"$. Del mismo modo, desde la prensa conservadora embarcada en campañas de moralización, se abogaba por medidas de aislamiento aplicables a colectivos de "degenerados" y "pervertidos" como los homosexuales: "Por mí, ya pueden construirles un barrio coquetón y perfumado a todos los invertidos", escribía por ejemplo Manuel Delgado Barreto en las páginas de La Acción $^{88}$. El confinamiento, la segregación de los sexos y la obligada castidad fueron así unos poco novedosos mecanismos eugenésicos propuestos por los católicos frente a la esterilización y sus indeseables efectos. Antonio Vallejo Nágera, a la vez que advirtió del fracaso de la esterilización terapéutica contra la hipersexualidad, insistió siempre en esta idea: "La moral individual es el mejor profiláctico contra las aberraciones del instinto" 89 .

El contexto de la guerra civil radicalizó la actitud defensiva de las derechas frente al desorden social que, una vez más, fue entendido también como un desorden sexual. La propia amenaza revolucionaria fue percibida como el desbordamiento de todas las bajas pasiones de la bestia humana ${ }^{90}$. La que ellos denominaron "guerra santa" fue presentada como una cruzada contra la inmoralidad y una defensa de todo lo que atentaba contra la familia cristiana ${ }^{91}$. En este contexto, Antonio Vallejo Nágera planteó la lucha como una empresa defensiva contra la "marejada de comunismo sexual" que asolaba la patria ${ }^{92}$. Destacó entonces la necesidad de construir una atmósfera saturada de elevadas esencias éticas, un ambiente moral protector del cuerpo social: "Contra el avasallador torrente materialista", sentenció, "no podemos oponer otro dique que los ideales religiosos y patrióticos". Y en el totalitario medio moral creado para la Nueva España, anunció, "el hombre casto y monógamo" podría contemplar con aires de superioridad todo aquello que le rodeaba $^{93}$. La forja de esta masculinidad civilizada y católica respondía al proyecto disciplinario de Ramiro de Maeztu al que hicimos referencia al comienzo de este artículo, un proyecto basado en una idea que estaba escrita, aseguró este último, en el pecho de cada hombre: la idea de "que la práctica del bien exige libertad, pero la del mal, cárceles y grilletes" $"$. Y los discursos del orden definieron el exacto sig-

86 Vallejo Nágera, Antonio: Eugenesia de la hispanidad..., p. 68.

87 Montero y Gutiérrez, Eloy: Neomalthusianismo, eugenesia..., p. 125.

88 Duque de G. [Delgado Barreto, Manuel]: "Política de costumbres. La campaña de saneamiento", La Acción (15 de mayo de 1924), p. 1.

89 Vallejo Nágera, Antonio: "Ilicitud científica...", p. 145.

90 Quintana, Lorenzo: ¡Franco! Al muchacho español, Barcelona, Librería Religiosa, 1940, p. 41.

91 Menéndez-Reigada, Ignacio G.: La Guerra Nacional Española ante la Moral y el Derecho. Bilbao, Editora Nacional, 1937, p. 9.

92 Vallejo Nágera, Antonio: Eugenesia de la hispanidad..., p. 73.

93 Vallejo Nágera, Antonio: Eugenesia de la hispanidad..., pp. 140 y 133.

94 Maeztu, Ramiro de: "El valor de la Hispanidad...", p. 18. 
nificado de estos conceptos del bien y del mal, que resultaron ser algo distinto, recordemos las palabras de Maeztu, a lo simplemente bueno y malo para el hombre ${ }^{95}$.

\section{Conclusiones}

En este artículo he pretendido llamar la atención sobre la capacidad significante y el papel contradictorio de la sexualidad masculina en los discursos y prácticas políticas de las derechas católicas en la España de entreguerras, particularmente durante los años veinte. He señalado la inestabilidad de la, en cualquier caso, fuerte vinculación entre feminidad y naturaleza por un lado, y de la masculinidad con cultura por otro, planteando que la pulsión sexual de los hombres sirvió para expresar miedos y ansiedades relacionados con la amenaza del desorden social y el peligro revolucionario. La figura del Don Juan, representativa de este instinto desordenado y del caos civilizatorio, fue cuestionada desde las derechas como mito masculino y referente nacional, a la vez que la constricción religiosa era considerada como única fuerza eficiente para el correcto gobierno de la sexualidad. Solo la fe constituía un remedio eficaz frente a la naturaleza peligrosa del don Juan y su falta de ideales.

Dentro del periodo abarcado por este estudio, el contexto político que más claramente mostró los rasgos y contradicciones propios de la política sexual de las derechas fue el correspondiente a la dictadura de Primo de Rivera. Iglesia y autoridades civiles y militares actuaron en tensa colaboración en un proyecto de regeneración de las costumbres y moralización de la sociedad. Pero el objetivo no fue solamente gobernar y ejercer la vigilancia del cuerpo femenino, siendo este aspecto central, sino también el de regular y encauzar la sexualidad masculina. Los privilegios de los hombres en las relaciones de género, cuya defensa era parte constitutiva del proyecto de la derecha católica, exigieron asimismo el recurso a una doble moral que permitiera su convivencia con los mandatos católicos de castidad y fidelidad matrimonial. Estas contradicciones permearon toda la política sexual de las derechas, con frecuencia poniendo de manifiesto sus inconsistencias, pero logrando en ocasiones, desde la apelación al dogma moral y a un único código de virtud, interpelar con éxito a las mujeres partícipes del malestar provocado por los excesos de la doble moral masculina.

En un ambiente de opinión receptivo hacia las propuestas eugenésicas, también las derechas adaptaron las nuevas ideas a su corpus doctrinal y a sus prioridades políticas. A pesar de la crisis de legitimidad de la ciencia que acompañó a la Gran Guerra y de la que, como vimos al comienzo de estas páginas, se hizo eco Ramiro de Maeztu, la autoridad de la verdad científica continuó en aquellos años siendo incuestionable para la mayoría. También permanecía prácticamente intacta su capacidad para articular discursos normativos y dictar políticas sociales. La eugenesia podía así contribuir al control de la sexualidad también desde principios católicos y plantea-

95 Lamentablemente, la libertad adquiría también un significado distinto según el sexo, y Maeztu pensaba que no existía nada más despreciable que una mujer libre. Y en relación con la definición del mal, tal y como ha señalado Luis Ocio en su interesante estudio sobre Ramiro de Maeztu, "comportamientos desviados como el feminismo, la homosexualidad, el sensualismo y el hedonismo habían de ser reprimidos, pues a lo que conducen es a la disolución de la sociedad, atacando sus bases morales de estabilidad y funcionamiento tradicionales". En Ocio Díaz de Otazu, Luis: Ramiro de Maeztu. Un monárquico en la II República, Bilbao, Universidad del País Vasco, 2014, pp. 351 y 444. 
mientos pronatalistas, y esta dimensión ordenadora y constrictiva de la nueva ciencia no pasó desapercibida a los sectores más conservadores, que recurrieron a ella de forma consistente. Pero a la vez, la adaptación requerida exigía el firme rechazo de los efectos para ellos más indeseados de la eugenesia, aquellos que llevaban incluso a separar la sexualidad de la procreación y derribaban los tradicionales muros de contención de la odiosa concupiscencia. El fantasma del instinto libre de ataduras asomaba tras el afán regulador de los eugenistas de izquierdas. Y en la lucha contra el desorden sexual, una amenaza que apareció siempre unida a la del desorden social, la religión y sus mandatos fueron presentados de nuevo como los gobernadores más eficaces del hombre y su naturaleza pecadora. 